
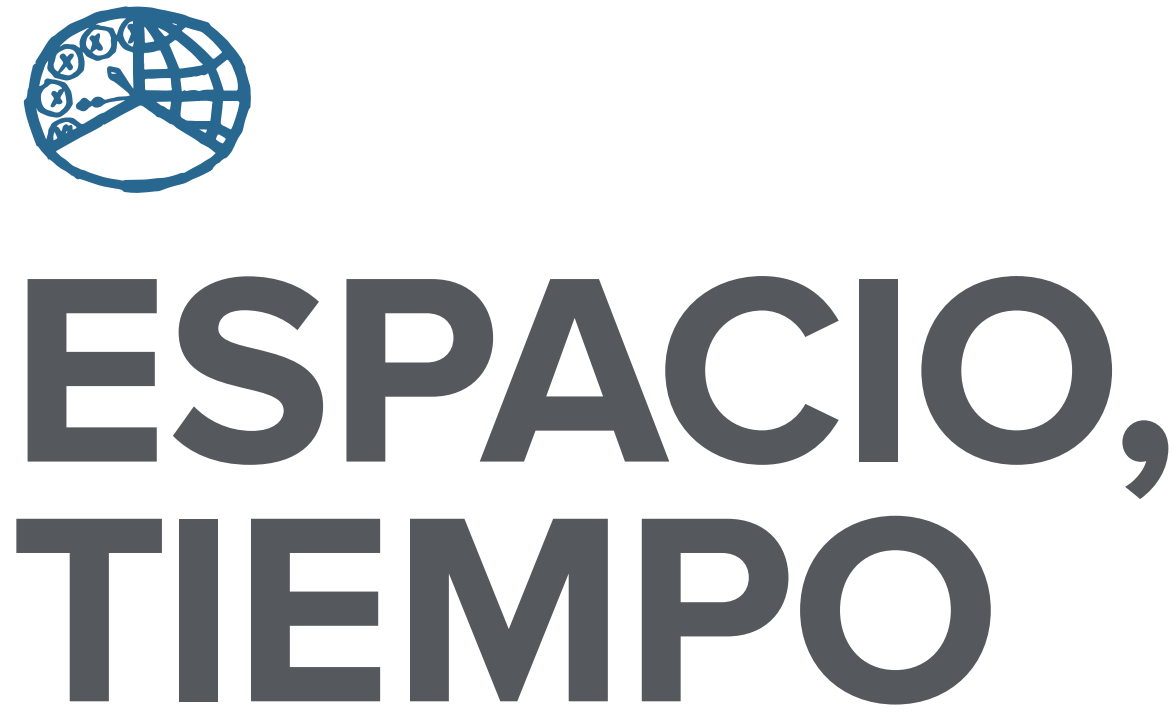

AÑO 2013

NUEVA ÉPOCA

ISSN 1130-4715

E-ISSN 2340-1478
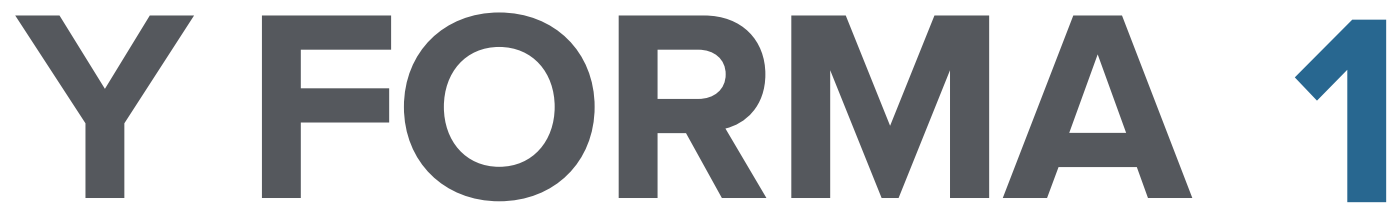

SERIE VII HISTORIA DEL ARTE

REVISTA DE LA FACULTAD DE GEOGRAFÍA E HISTORIA 

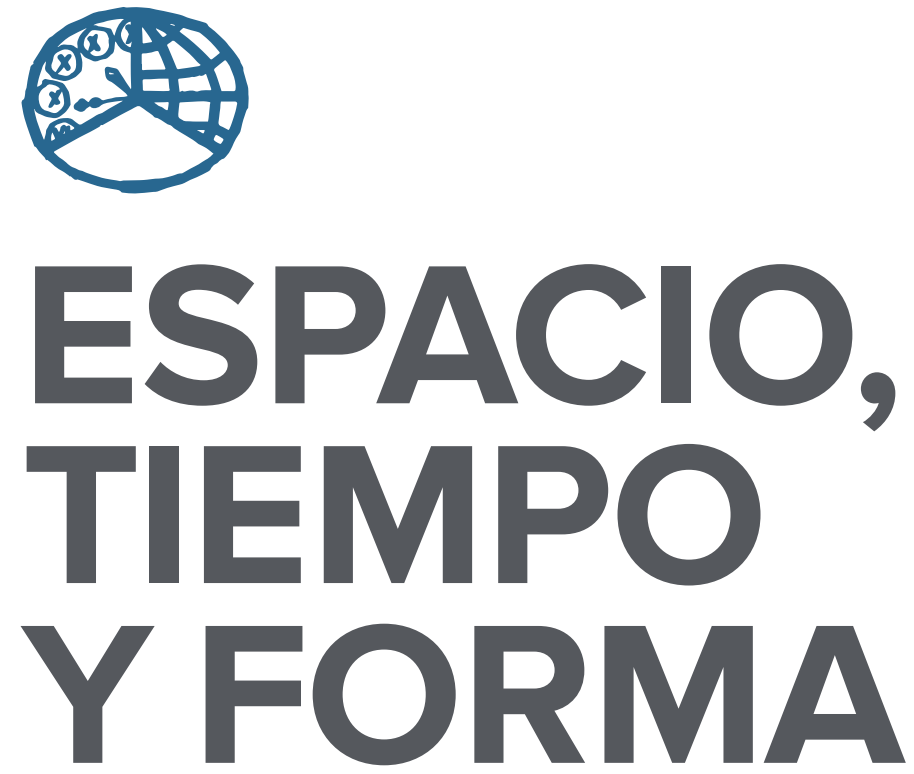

AÑO 2013

NUEVA ÉPOCA

ISSN $1130-4715$

E-ISSN 2340-1478

SERIE VII HISTORIA DEL ARTE

REVISTA DE LA FACULTAD DE GEOGRAFÍA E HISTORIA

http://dx.doi.org/10.5944/etfvii.1.2013

\section{UกED}

UNIVERSIDAD NACIONAL DE EDUCACIÓN A DISTANCIA 
La revista Espacio, Tiempo y Forma (siglas recomendadas: ETF), de la Facultad de Geografía e Historia de la UNED, que inició su publicación el año 1988, está organizada de la siguiente forma:

$$
\begin{aligned}
& \text { SERIE I - Prehistoria y Arqueología } \\
& \text { SERIE II - Historia Antigua } \\
& \text { SERIE III - Historia Medieval } \\
& \text { SERIE IV - Historia Moderna } \\
& \text { SERIE V - Historia Contemporánea } \\
& \text { SERIE VI - Geografía } \\
& \text { SERIE VII - Historia del Arte }
\end{aligned}
$$

Excepcionalmente, algunos volúmenes del año 1988 atienden a la siguiente numeración:

$$
\begin{aligned}
& \mathrm{N}^{\circ} 1 \text { - Historia Contemporánea } \\
& \mathrm{N}^{\circ} 2 \text { - Historia del Arte } \\
& \mathrm{N}^{\circ} 3 \text { - Geografía } \\
& \mathrm{N} .^{\circ} 4 \text { - Historia Moderna }
\end{aligned}
$$

ETF no se solidariza necesariamente con las opiniones expresadas por los autores.

Espacio, Tiempo y Forma, Serie vII está registrada e indexada, entre otros, por los siguientes Repertorios Bibliográficos y Bases de Datos: DICE, ISOC (CINDOC), RESH, IN-RECH, Dialnet, e-spacio, UNED, CIRC, MIAR, FRANCIS, PIO, Ulrich's, SUDOC, 2DB, ERIH (ESF).

\author{
UNIVERSIDAD NACIONAL DE EDUCACIÓN A DISTANCIA \\ Madrid, 2013 \\ SERIE VII · HISTORIA DEL ARTE (NUEVA ÉPOCA) N. ${ }^{\circ} 1,2013$ \\ ISSN $1130-4715 \cdot$ E-ISSN 2340-1478 \\ DEPÓSITO LEGAL \\ $M-21.037-1988$ \\ URL \\ ETF VII · HISTORIA DEL ARTE · http://revistas.uned.es/index.php/ETFVII \\ DISEÑO Y COMPOSICIÓN \\ Ángela Gómez Perea · http://angelagomezperea.com \\ Sandra Romano Martín · http://sandraromano.es \\ Impreso en España · Printed in Spain
}

(c) (1) (8) Esta obra está bajo una licencia Creative Commons

Reconocimiento-NoComercial 4.0 Internacional. 


\title{
TRANSFORMACIONES EN EL RETABLO MAYOR DE SAN MIGUEL ARCÁNGEL DE LAZKAO (GIPUZKOA): DEL BARROCO AL NEOCLASICISMO
}

\section{CHANGES IN THE MAIN ALTARPIECE OF SAINT MICHAEL THE ARCHANGEL IN LAZKAO (GIPUZKOA): FROM BAROQUE TO NEOCLASSICISM}

\author{
Fernando R. Bartolomé García y Laura Calvo García² \\ Recibido: 5/06/2013 - Aprobado: 3/10/2013 \\ http://dx.doi.org/10.5944/etfvii.1.2013.7197
}

\section{Resumen}

El retablo mayor de la localidad guipuzcoana de Lazkao fue realizado por Juan de Ursularre en I683, siguiendo los parámetros de la retablística barroca. Queriendo engrandecer su aspecto, fue paulatinamente transformado durante el siglo xvili. Por ello se concibió un nuevo cascarón con pinturas enviadas desde Madrid y más tarde se adecuó a los nuevos gustos neoclásicos mediante una radical reforma realizada en i79i que consistió en eliminar todo atisbo de decoración barroca.

\section{Palabras clave}

Transformación; retablo barroco; Juan de Ursularre; Neoclasicismo; Diego Díaz del Valle; policromía; escuela madrileña.

\section{Abstract}

The main altarpiece of Lazkao, Gipuzkoa, was done by Juan de Ursularre in I683, following the Baroque guidelines. It was transformed during the $18^{\text {th }}$ century to enlarge its appearance. Due to this, it was conceived anew with paintings sent from Madrid. Later, in I79I, the altarpiece was neoclassized with a radical transformation that consisted of the removal of the whole Baroque decoration.

Keywords

transformation; Baroque altarpiece; Juan de Ursularre; Neoclassicism; Diego Díaz del Valle; polychromy; school of Madrid.

1. Profesor Titular de Universidad. Departamento de Historia del Arte y Música, Facultad de Letras, Universidad del País Vasco upv/EHu.

2. Personal investigador. Departamento de Historia del Arte y Música, Facultad de Letras, Universidad del País VasCO UPV/EHU. 


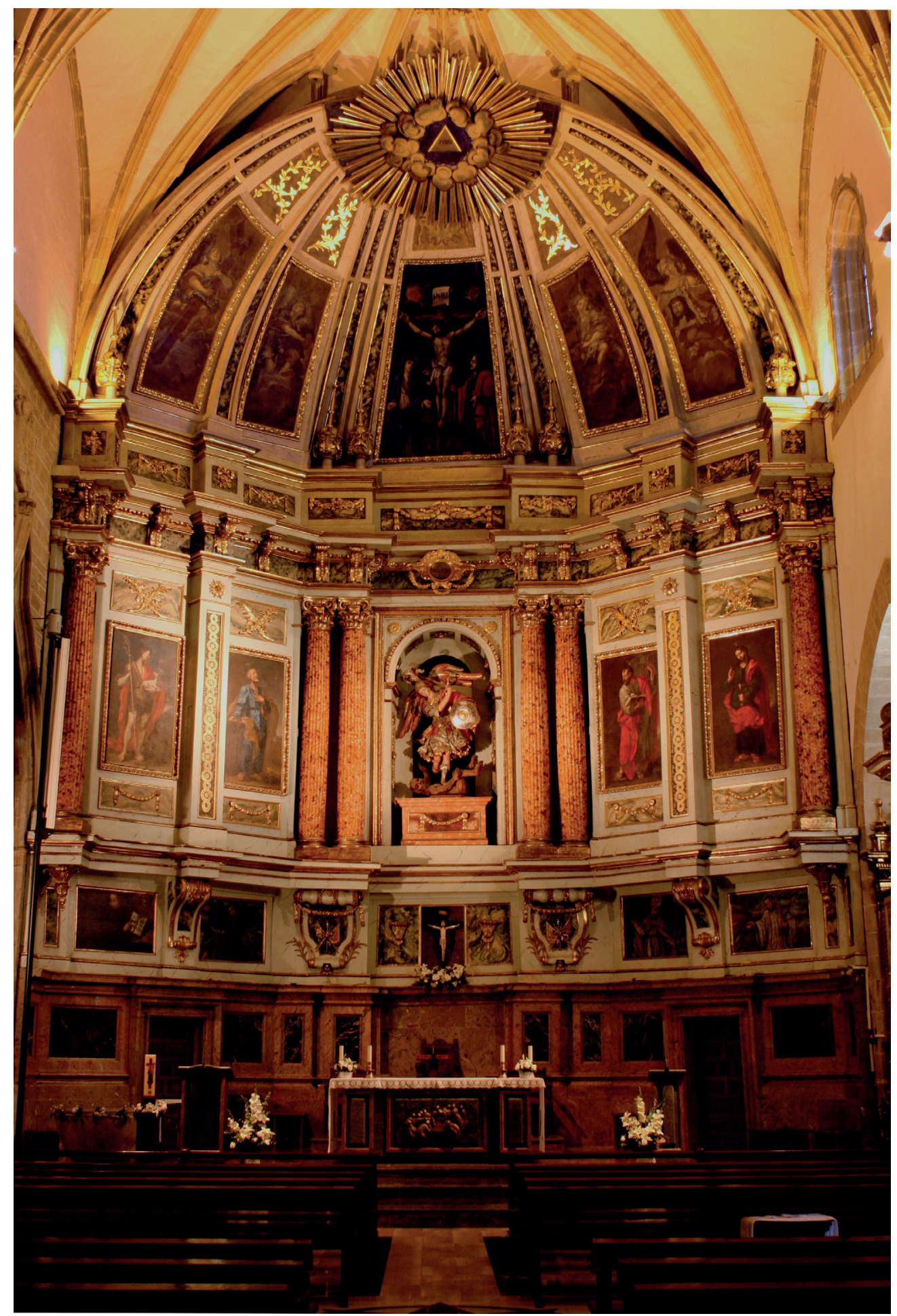

FIGURA 1. RETABLO MAYOR DE LA IGLESIA DE SAN MIGUEL, LAZKAO (GIPUZKOA) Las fotos 1-4 y 6-9 están realizadas por los autores. 

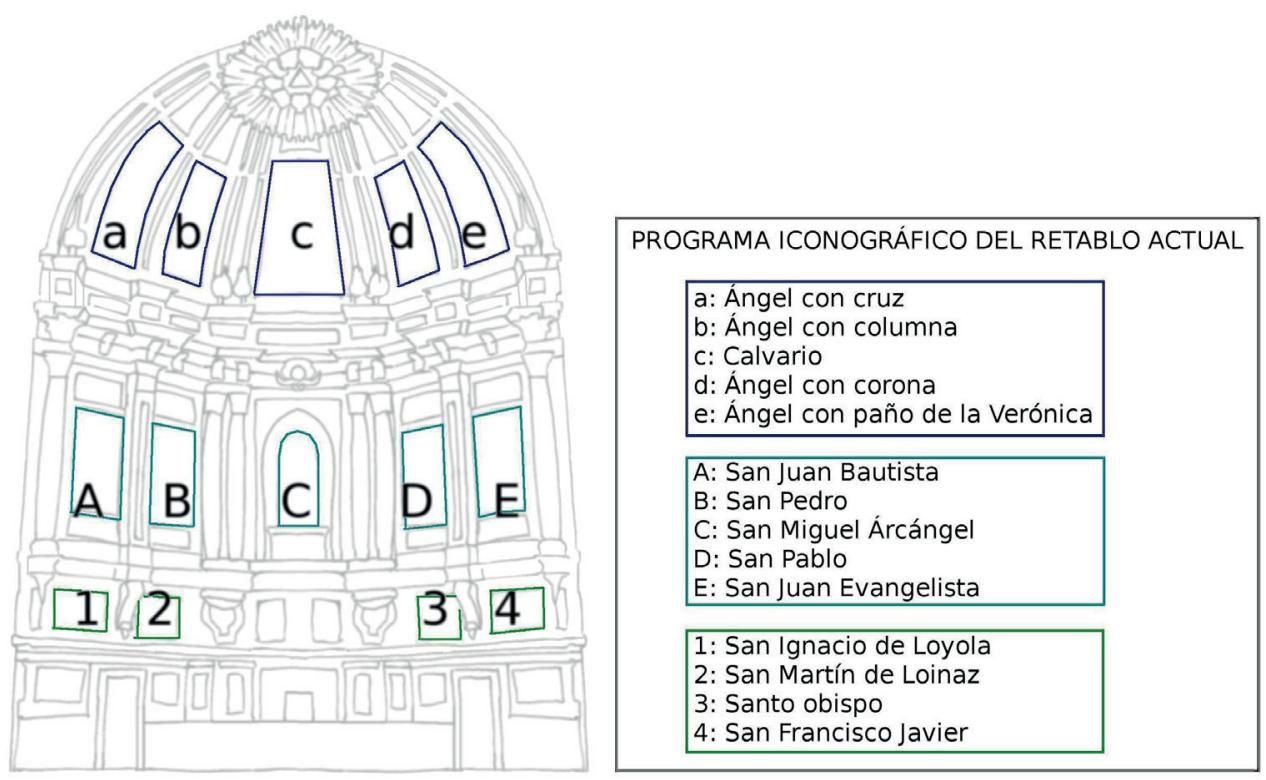

FIGURA 2. PROGRAMA ICONOGRÁFICO ACTUAL Retablo mayor de la iglesia de San Miguel, Lazkao (Gipuzkoa).

ES HABITUAL QUE LAS OBRAS DE ARTE sufran transformaciones a lo largo del tiempo, adaptándose a los nuevos gustos imperantes en cada época. No es por ello extraño que el retablo mayor de la parroquia de Lazkao esconda bajo una apariencia neoclásica su esencia barroca. Fue construido por el arquitecto Juan de Ursularre hacia I680 y contaba con un solo cuerpo formado por dos grandes pinturas a cada lado flanqueando la talla de San Miguel Arcángel. Poco tiempo después, a comienzos del siglo xvılı, se reformaba el remate para alojar unos lienzos enviados desde Madrid. Sin embargo, la transformación más profunda se llevó a cabo en I79i cuando, en un intento de neoclasicización, se despojó al altar de todo su aparato decorativo y se le proporcionó un revestimiento pictórico acorde a las nuevas modas. Fue tal el cambio sufrido en el conjunto del retablo que, aunque la bibliografía constataba la construcción de este altar, se daba por desaparecido en la actualidad (FIGURA I).

Las primeras referencias documentales que dan noticia de las obras del nuevo retablo mayor de San Miguel y de los colaterales de la Virgen y San José se remontan a I680. En ese año se registran pagos entre los que se incluyen la tala y el transporte de nogales para la construcción del nuevo altar ${ }^{4}$. Juan de Ursularre se encargó de proporcionar una primera traza para este retablo barroco. Diseñó un altar con remate en forma de cascarón en el que no se añadieron columnas salomónicas, por lo que aún no podemos considerarlo de estilo churrigueresco. En la documentación se insiste en que sea de "proporción ovalada» y de planta ochavada. Estaba

3. Cendoya Echániz, Ignacio: El retablo barroco en el Goierri: la constante academicista en Gipuzkoa. San Sebastián, Fundación Social y Cultural Kutxa, 1992, pp. 241-242. AstıAZARÁıN ACHÁBAL, M. a Isabel: «El arquitecto Juan de Usularre y Echeverría y sus proyectos retablísticos en Guipúzcoa», Anales de historia del arte, 5 (1995), pp. 77-92.

4. Se paga a García de Albisu y Pedro de Galarza por trabajos de carpintería y otras labores desde 1680. Archivo Histórico Diocesano de San Sebastián (DEAH), Lazkao, San Miguel Arcángel, Libro de fábrica, 1650-1726, f. 154V. 
compuesto de un banco, un único cuerpo dividido en cuatro calles por columnas de fuste estriado y capitel corintio y un remate semicircular5. La decoración era naturalista, pero no excesiva, compuesta por motivos vegetales «de buen relieve y muy garifos ${ }^{6}$, carnosas hojarascas, modillones y tarjetas, que nos anticipan el devenir de la retablística durante las últimas décadas del siglo xvıl, aunque todavía recoge elementos clasicistas como las columnas estriadas de corte clásico. Es un retablo mixto en el que se conjugan escultura y pintura. Está presidido por una talla de San Miguel y un Calvario en el remate. En las cuatro calles laterales del cuerpo central nos encontramos con los lienzos de San Juan Bautista, San Pedro, San Pablo y San Juan Evangelista, mientras que en el banco debieron de existir dos pinturas de San Ignacio y San Francisco Javier. El sagrario, no conservado en la actualidad, era de tipo tabernáculo ${ }^{7}$, siguiendo modelos madrileños (FIGURA 2).

El prestigioso arquitecto Juan Ursularre Echeverría se considera figura esencial en el desarrollo del retablo barroco en Gipuzkoa ${ }^{8}$. Su formación y los primeros pasos profesionales los realizó en el foco madrileño a la sombra de relevantes arquitectos de retablos como el hermano Francisco Bautista y Pedro de la Torre. Hacia I670 regresa a su tierra natal, donde lleva a cabo la mayor parte de su actividad profesional. Su habilidad como tracista y arquitecto de retablos queda de manifiesto en los conjuntos realizados en Madrid, Gipuzkoa, Toledo y Navarra. Ursularre, por su formación madrileña junto a Francisco Bautista Medina, tracista del Colegio Imperial de la Compañía de Jesús, conocería las últimas soluciones empleadas en la retablística más innovadora, que llegaron a Gipuzkoa a través de la traza que el hermano Bautista diseñó para la iglesia de Santa María la Real de Azkoitia en I66o, obra que sirvió de modelo para el retablo mayor del santuario de Nuestra Señora La Antigua en Orduña (Bizkaia) y también, sin duda, la que inspiró a Juan de Ursularre para el retablo mayor de Lazkao'. De esta manera nuestro retablo se convierte, tras

\footnotetext{
5. DEAH, Lazkao, San Miguel Arcángel, Escritura del convenio para el dorado del altar mayor, 1791, s/f.

6. Garifo: bien compuesto y adornado (DRAE 1739, s. v. xarifo,-fa).

7. DEAH, Lazkao, San Miguel Arcángel, Escritura de capitulaciones, peticiones y licencia para la realización del retablo mayor y colateral de la iglesia de Lazkao, 1684.

8. Juan de Ursularre y Echeverría, nacido en Gaintza (Gipuzkoa), fue un conocido arquitecto de la segunda mitad del siglo XVII. Entre sus obras tenemos el retablo baldaquino de la capilla del Cristo de los Dolores en la iglesia de la Venerable Orden Tercera de San Francisco de Madrid (traza del hermano Francisco Bautista), de 1664; el retablo mayor de Santa María de Beasain (Gipuzkoa) de 1670; las trazas en 1671 para los retablos de Nuestra Señora de la Antigua en Antzuola y para el retablo del Cristo en San Juan de Uzarraga; dos colaterales para la iglesia de San Miguel de Gaintza, realizados en 1671; el sagrario y otras obras en la iglesia de San Juan Bautista de Olaberria en 1674; el colateral de Nuestra Señora del Rosario en la iglesia de San Miguel de Idiazabal; los altares desaparecidos de San Pedro, Santiago y San Miguel de la iglesia parroquial de Mutriku, de 1676; el retablo mayor, la custodia y cuatro santos de la iglesia parroquial de Portillo (Toledo), en 1676; las trazas para dos colaterales de San Miguel arcángel y Nuestra Señora del Rosario para la iglesia de la Santa Fe de Zaldibia, en 1677; el retablo de San Bartolomé de Elgoibar, de 1682 (desaparecido); el retablo mayor y colaterales de San Miguel de Lazkao, de 1683; los diseños para verificar dos retablos colaterales de la iglesia parroquial de Altzo Muino, en 1686; el retablo de Etxarri-Aranatz (Navarra), en 16870 la traza del retablo para la iglesia del convento de las agustinas recoletas de Pamplona. Murugarren, Luis: Anzuola, Uzárraga y Elosua. San Sebastián, Caja de Ahorros Municipal de San Sebastián, 1975; Tovar, Virginia: Arquitectos madrileños de la segunda mitad del siglo XVII. Madrid, CSIC, 1975; CENDOYA ECHÁNIZ, Ignacio: op. cit.; ASTIAZARÁIN ACHÁBAL, M. ${ }^{a}$ Isabel: op. cit.; VÉLEZ ChAURRI, José Javier: «La escultura barroca en el País Vasco. La imagen religiosa y su evolución», Ondare, 19 (2000), pp. 45-115; VÉLEZ ChAURRI, José Javier: «El retablo barroco», en ECHEVERRÍA GoÑI, Pedro Luis: Erretaulak. Retablos, T.I. Vitoria, Departamento de Cultura del Gobierno Vasco, 2001, p. 253.

9. Bartolomé García, Fernando R. y Zorrozua Santisteban, Julen: «Antonio de Alloytiz y los retablos mayores de la Antigua de Orduña (Vizcaya) y Santa María de Azkoitia (Guipúzcoa). Una traza del hermano Bautista», en
} 
Azkoitia, en uno de los primeros retablos cascarón de Gipuzkoa y junto con el de Labastida (Álava), de i672, en uno de los primeros del País Vasco.

Como ya hemos comentado, la obra se inició hacia I68o, cuando comenzaron los primeros pagos de materiales. El patronato de la iglesia hizo una contratación directa con Juan de Ursularre, sin sacar la obra a subasta pública y sin contar con la licencia del obispado, obligatoria para cualquier obra de cierta envergadura. No obstante, la obra no fue protocolizada hasta el 28 de noviembre de I683, momento en el que se hizo referencia a todas las transformaciones que se debían llevar a cabo sobre una traza previa ${ }^{\text {Io }}$. Entre las nuevas modificaciones acordadas con Juan de Ursularre estaba la reducción de las dimensiones del retablo, quitando una de las dos pinturas de cada lado del cuerpo principal, la inclusión de una tabla con la Virgen y San Juan en el remate y un nuevo sagrario tabernáculo «en forma calada con su trono y peana para poner la custodia». Igualmente, se pide decorar la puerta de la sacristía «con su marco tallado y tarjeta encima y por consiguiente en el otro lado por la correspondencia y proporción que pide la obra».

Los trabajos se habían comenzado sin la requerida licencia. Por ello, en i684 se pide permiso a la diócesis de Pamplona alegando que «la iglesia parroquial se halla sin retablo principal, el cual necesita precisamente para el servicio de su culto divino respecto de ser de grande poblazion y vecinos». El fiscal general del obispado, por su parte, alegó que debía negarse el permiso a esta parroquia porque ni se disponía de las cantidades necesarias para sufragar los gastos ni de las fianzas debidas y además el precio era excesivo, dado que no se había sacado a candela. A pesar de estos impedimentos, la licencia fue concedida el I3 de abril de i684 con la condición expresa de que se sacara a candela para adjudicárselo al mejor postor, sin que se encargara de forma directa a Ursularre ${ }^{\text {II }}$, aunque finalmente la obra se concertó con este arquitecto. Es evidente que la intención de los contratantes era realizar un buen retablo con un maestro reputado al que seguramente conocerían por su importante labor en Gipuzkoa. Las limitaciones que el obispado impuso para conceder la licencia no debieron de gustar a los patronos, ya que se reducía considerablemente el tamaño del altar, así que es probable que decidieran seguir la primera traza dada por Ursularre, manteniéndose las cuatro calles con las cuatro pinturas.

El plazo de finalización del retablo mayor y sus colaterales se fijó para finales de I685. La iglesia pagaba los materiales y cedía una vivienda para residencia del artista, donde al parecer Juan de Ursularre estuvo viviendo durante tres años. En cuanto al cobro, el arquitecto debía recibir 1500 ducados en especie: al comienzo 50 fanegas de trigo; para I684 otras 50 fanegas y toda la harina, tocino y sidra que quisiera, a

Fernández Gracia, Ricardo. (coord.): Pulchrum. Scripta varia in honorem María Concepción García Gainza. Gobierno de Navarra, Universidad de Navarra, 2011, pp. 142-149.

10. El patronato era mixto. Firmaron la escritura Ignacio de Elósegui, vicario perpetuo, el licenciado Juan Bautista de Yerga y Juan Ochoa de Arín y Lazcano, beneficiados, por parte de la iglesia; Sebastian de Ímaz, alcalde y juez ordinario; Pedro de Chinchurreta y Juan de Altolaguirre, regidores de las comunidades eclesiásticas y secular y Baltasar de Elósegui, mayordomo, por parte del ayuntamiento y por otra parte Juan de Ursularre y su mujer. CENDOYA ECHÁNIZ, Ignacio: op. cit., p. 241.

11. DEAH, Lazkao, San Miguel Arcángel, Escritura de capitulaciones, peticiones y licencia para la realización del retablo mayor y colateral de la iglesia de Lazkao, 1684, f. 2 v. 
descontar de la cantidad acordada y el resto del importe, hasta completar el pago, lo cobraría de las primicias de la iglesia. Finalmente cobró algo más, I6606 reales, debido a que corría prisa acabar la obra, recibiendo el finiquito el 29 de septiembre de $1686^{12}$.

En origen, el retablo poseía un banco con pinturas, una calle central con figuras de talla, dos calles laterales con lienzos pintados de gran tamaño y un remate en forma de cascarón. Los lienzos del primer cuerpo nos presentan a San Juan Bautista y a San Pedro en el lado del Evangelio y a San Pablo y San Juan Evangelista en el lado de la epístola (FIGURA 3).

San Pedro, el primer papa, ocupa el lugar más importante, junto a la talla del titular. El elegido de entre los apóstoles se apoya en una columna baja y sostiene las llaves, que nos recuerdan su autoridad en la Iglesia. Eleva la mirada hacia lo alto y acerca la mano al pecho en señal de dolor, mientras de sus ojos caen unas lágrimas. $\mathrm{Su}$ rostro nos presenta a un hombre anciano de barbas blancas, gran vida espiritual y anatomía enjuta que queda envuelta en unas vestiduras almidonadas. San Pablo, el apóstol de los gentiles, se muestra como un hombre maduro lleno de fuerza y vitalidad. Sujeta con una complicada torsión de brazo una gran espada que simboliza su afán predicador y rememora su martirio, mientras que con la otra mano mantiene abierto el libro de los Evangelios. El barroquismo se hace presente en la diagonal que alinea su figura desde el pie hasta la mano; su postura es, de los cuatro personajes de la calle central, la que sugiere más movimiento, debido al giro de la cabeza, la elevación de la pierna sobre un pequeño desnivel y el contrapposto que ello genera.

En las calles exteriores hacen pareja San Juan Bautista y San Juan Evangelista. El Precursor acoge en su regazo al Agnus Dei, con el que intercambia una tierna mirada, y con la mano derecha aguanta con decisión una larga cruz en la que se enrolla una filacteria. Cubre su cuerpo una túnica corta de piel de camello que deja a la vista parte de su pecho, brazos y piernas y sobre ella lleva una túnica carmín que alude a su futuro martirio. En el otro extremo se encuentra San Juan Evangelista, quien, absorto, bendice un cáliz dorado, simbolizando el triunfo de Dios sobre el mal, como se desprende de uno de los episodios más celebres de este santo que se recoge en la Leyenda Dorada.

El estilo de las pinturas hace que debamos situarlas en el último tercio del siglo xvil, momento en el que se está trabajando en la fábrica del retablo mayor. Son lienzos de gran calidad, y aunque hallamos pequeñas diferencias de carácter formal entre ellos debidas, posiblemente, a la copia de estampas, son muchas más las características estilísticas que comparten, por lo que creemos que nos encontramos ante un mismo autor. El pintor muestra un buen conocimiento de la anatomía humana y de la perspectiva, empleando un cuidado dibujo y una pincelada enérgica y bien resuelta. Las figuras se perfilan con una línea rojiza apoyada sobre una

12. DEAH, Lazkao, San Miguel Arcángel, Libro de fábrica, 1650-1726, f. 158 (1686). 1500 d. que se le debían al maestro en virtud de la escritura. Más 106 r. y medio de vellón que se le ha dado de más por ser preciso que la obra se acabase: 16606 reales y medio. Al maestro que hizo la obra se le ofreció residir en la casa del vicario. CENDOYA ECHÁNIZ, Ignacio.: op. cit., pp. 241-242. 


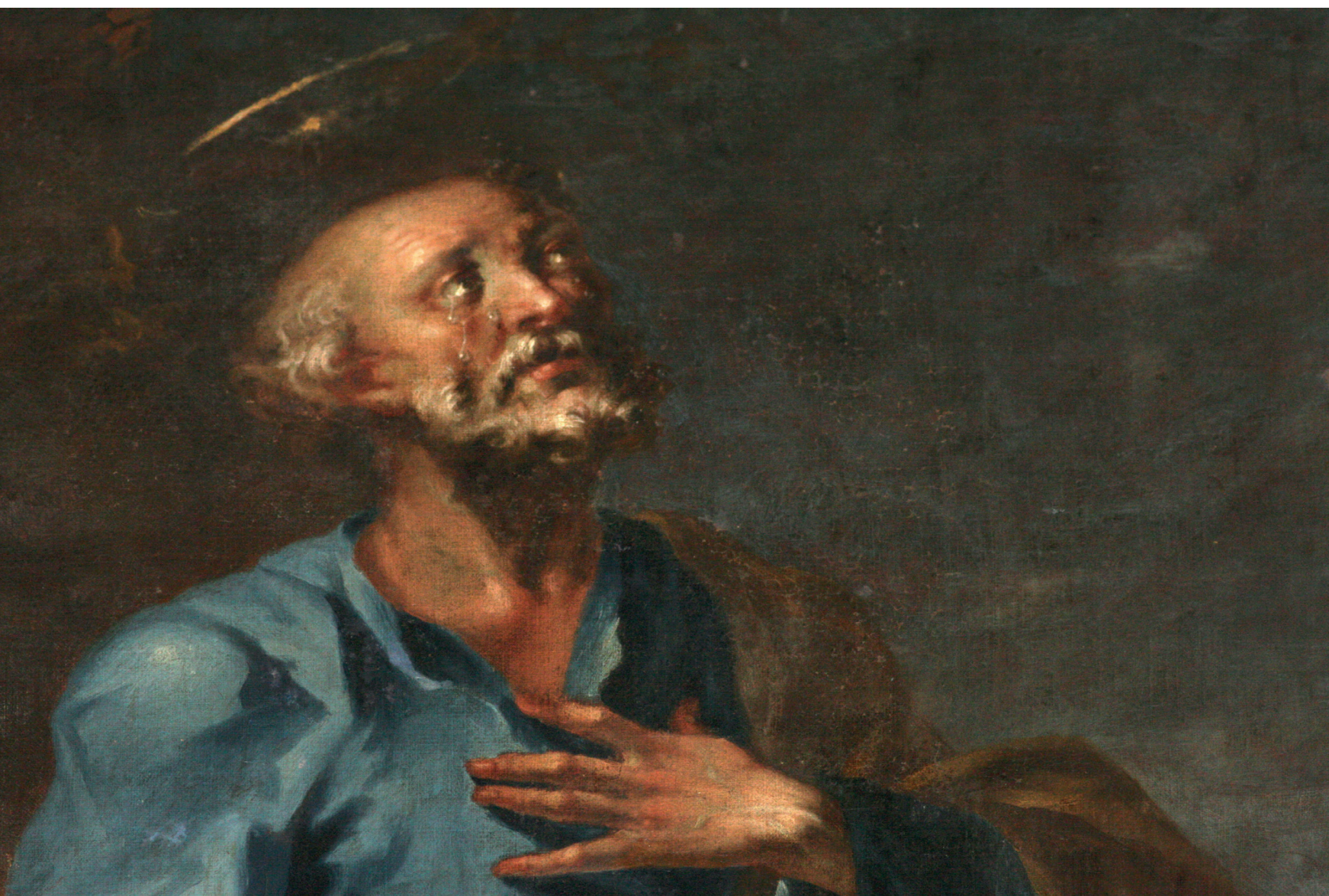

FIGURA 3. SAN PEDRO

Primer cuerpo del retablo mayor de la iglesia de San Miguel, Lazkao (Gipuzkoa).

preparación del mismo tono. En su paleta predominan los tonos terrosos, rojos y amarillos, que contrastan con otra gama fría de azules y verdes, avivados con potentes toques de luz que se logran mediante sutiles pinceladas blancas. La luz, que proviene del ángulo superior izquierdo, genera una sombra en el suelo al lado derecho de los personajes. En los cuatro lienzos se emplea una técnica habitual entre los pintores barrocos, por la que los fondos se resuelven con una zona más oscura al lado izquierdo y un paisaje tormentoso en la mitad derecha, que unido a la utilización de focos de luz dirigidos, hacen destacar la figura humana y consiguen que la atención se centre exclusivamente en ella. Un recurso que delata la personalidad del pintor es el empleo de una aureola con una estrella de luz en los cuatro santos y unas sandalias de tiras muy características. 
Las composiciones son sencillas, supeditadas al uso de estampas flamencas, como se puede advertir en el lienzo San Pablo que reproduce una estampa de la vida de Santiago Apóstol dibujada por el manierista Maarten de Vos (1532-I603) ${ }^{\mathrm{r}}$. La maniera del grabado está relacionada con una pose un tanto artificial, con un pie sobre un escalón que contribuye a exagerar el contrapposto y que genera cierto desequilibrio. Sin embargo nuestro pintor no copió literalmente la escena, ya que sustituyó el cayado y la calabaza propios del santo peregrino por una gran espada asida gracias a una complicada torsión de muñeca muy bien resuelta que no aparece en el grabado (FIGURAS 4 Y 5).

Pese a que los cuatro lienzos del retablo no están firmados, su gran calidad nos indica que proceden un centro importante de producción pictórica, probablemente Madrid. Detrás de su contratación podría estar algún personaje destacado de Lazkao, lo que nos hace pensar en los Lazcano o en los Iztueta, que trabajaron en Madrid en el entorno cortesano ${ }^{\mathrm{I}}$. Miguel de Iztueta, alcalde de Lazkao en I679, debió de participar en la gestación del nuevo retablo, por lo que pudo influir en la elección de los maestros. Además resulta significativo que unos años después, ya residiendo en la corte, regalara cuatro lienzos madrileños para el cascarón, como veremos más adelante. También tenemos que tener en cuenta que Juan de Ursularre, el arquitecto que se encargó del retablo, estaba familiarizado con el entorno artístico madrileño, lo que nos hace pensar que pudiera haber recurrido a algún pintor de su círculo profesional.

Una vez terminado el retablo mayor y sus dos colaterales, era preciso que se policromaran, pero probablemente por motivos económicos solo se decidió dorar el sagrario y la caja del titular San Miguel. En I706 se pidió la licencia necesaria ${ }^{15}$ y se contrató el trabajo con el pintor-dorador Pedro Francisco de Landa, vecino de Riezu, Navarra ${ }^{16}$. Una vez finalizado el trabajo fue examinado por Juan de Arraiz ${ }^{17}$, quien valoró lo ejecutado y determinó que se volviera a dorar el nicho de San Miguel por haberlo dejado imperfecto ${ }^{18}$. Parte del pago se realizó gracias a las aportaciones particulares de Eugenia Enríquez, mujer de Baltasar de Lazcano y Espina ${ }^{\mathrm{I}}$. En $\mathrm{I} 7 \mathrm{I} 5$ también se doró el colateral de Nuestra Señora de la Concepción y los marcos de este retablo y del altar mayor ${ }^{20}$.

No habían pasado ni tres décadas desde la finalización del retablo mayor cuando se quisieron realizar las primeras reformas, que datan de hacia I7ı, año en el

13. Hollstein, F.W.H.: Hollstein's Dutch and Flemish etchings, engravins and woodcuts, ca. 1450-1700, v. 46. Maarten De Vos. Plates Part II. Rotterdam, The Netherlands, Sound \& Vision Interactive, 1995, p. 23.

14. Miguel de Iztueta fue fiscal del Protomedicato y síndico de las Descalzas Reales y su hermano Juan Bautista era guardián de las Reales Caballerizas de la Reina.

15. La licencia costó 28 reales. DEAH, Lazkao, San Miguel Arcángel, Libro de fábrica, 1650-1726, s/f.

16. Sobre Pedro Francisco Landa: García GainzA, M. ${ }^{a}$ Concepción (dir.): Catálogo Monumental de Navarra. III. Merindad de Olite. Comunidad Foral de Navarra, Institución Príncipe de Viana, 1985, p. 127. Dorado de unas tallas en la iglesia de San Miguel de Larraga (1699-1700).

17. El examinador cobró 90 reales por su trabajo. DEAH, ibid., s/f, 1709.

18. DEAH, ibid., f. 179 y siguientes.

19. DEAH, Lazkao, San Miguel Arcángel, Licencia para dorar el sagrario del retablo mayor y pagos, 1706-1707.

20. Este trabajo lo realizó el pintor dorador Bartolomé de Arregui. DEAH, Lazkao, San Miguel Arcángel, Libro de fábrica, $1650-1726$, s/f. 

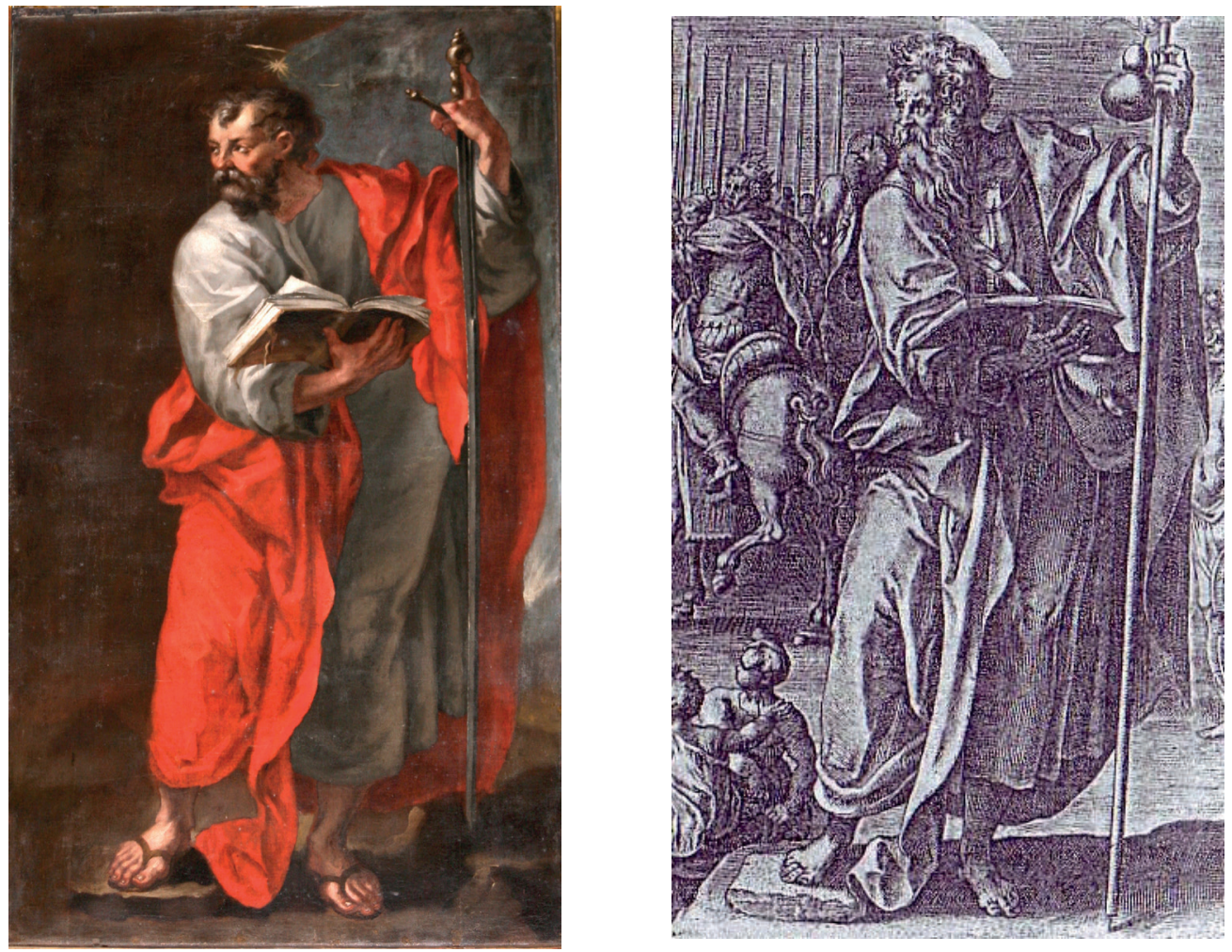

FIGURA 4 ( (I). SAN PABLO

Primer cuerpo del retablo mayor de la iglesia de San Miguel, Lazkao (Gipuzkoa).

FIGURA 5 (D). SANTIAGO APÓSTOL (DETALLE)

Maarten de Vos. (HollsteIn, F.W.H.: Hollstein's Dutch and Flemish etchings, engravins and woodcuts, ca. 1450-1700, v. 46. Maarten de Vos. Plates Part II. Rotterdam, The Netherlands, Sound \& Vision Interactive, 1995, p. 23).

que Miguel de Iztueta regalaba y enviaba cuatro pinturas de escuela madrileña para engalanar el cascarón ${ }^{21}$. Este personaje, oriundo de Lazkao, donde nació en I $648^{22}$, ejerció como alcalde de esta localidad en I679, por lo que es probable, como ya hemos comentado, que tuviera una importante implicación en la contratación de dicho retablo, en el que ya se trabajaba al menos desde i68o. En i695 Miguel de Iztueta contrajo matrimonio con María Bautista de Elósegui Zufiria ${ }^{23}$ y poco después se trasladó a vivir a Madrid, donde ejerció los cargos de fiscal del Real Protomedicato de Castilla ${ }^{24}$ y síndico general del convento de las descalzas de la villa

21. DEAH, ibid., 1710

22. DEAH, Lazkao, San Miguel Arcángel, 2. ${ }^{\circ}$ Bautismos, f. 26v, 15/10/1648.

23. DEAH, Lazkao, San Miguel Arcángel, 3. ${ }^{\circ}$ Matrimonios, f. 3r, 14/02/1695. Hacia 1700 nacía Francisca, su única hija. Su mujer era natural de Lazkao, donde nació en 1676: DEAH, Lazkao, San Miguel Arcángel, 2. ${ }^{\circ}$ Bautismos, f. 77r, $08 / 18 / 1676$.

24. IBORRa, Pascual: Historia del Protomedicato en España (1477-1822). Valladolid, Universidad de Valladolid, 1987, p. 71. BARRIO OGAYAR, Jesús: La organización protomedicato en España. Granada, Universidad de Granada, 1976. 


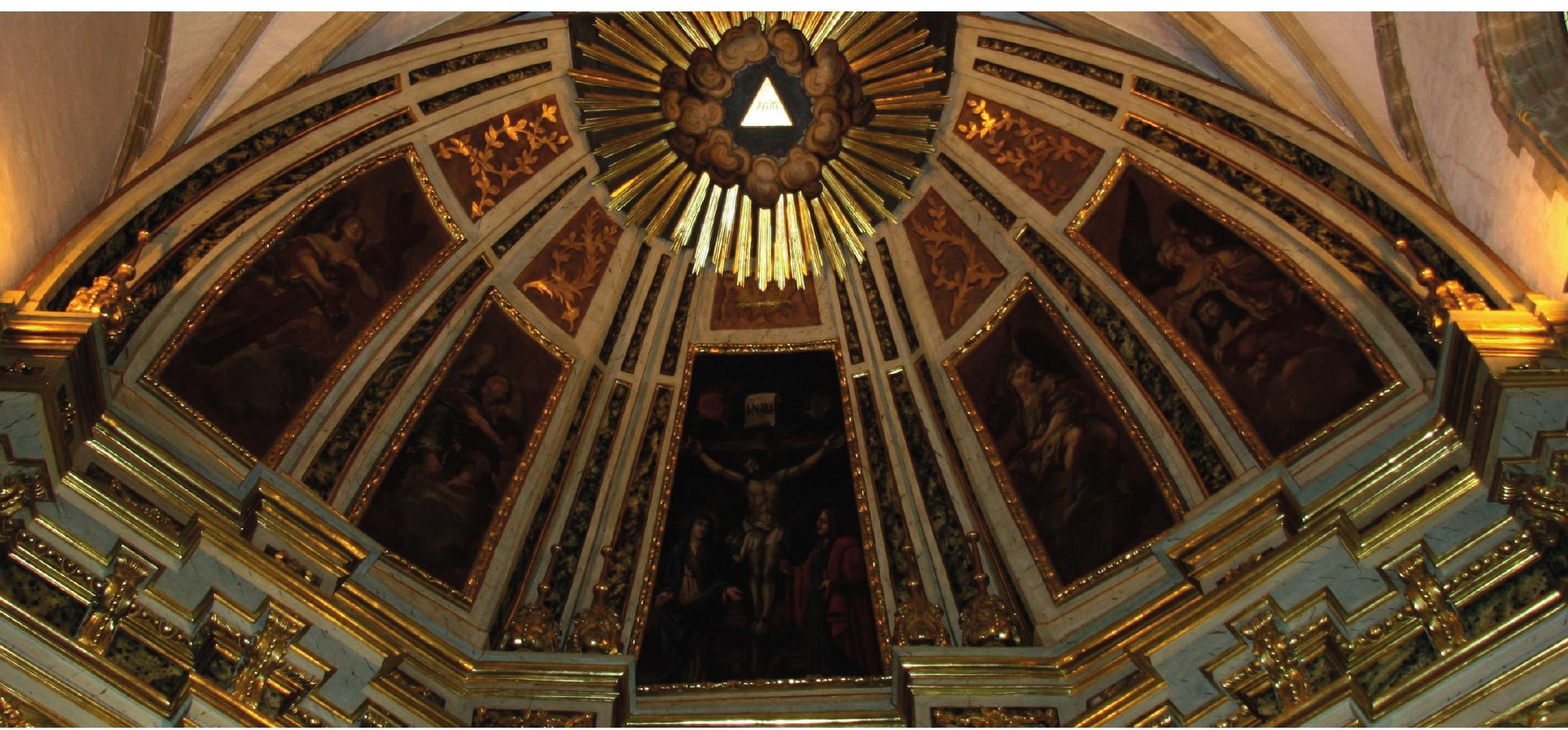

FIGURA 6. CASCARÓN

Retablo mayor de la iglesia de San Miguel, Lazkao (Gipuzkoa).

madrileña ${ }^{25}$. Estas pinturas, que representan a cuatro ángeles con las arma Christi, fueron adaptadas al cascarón del retablo mayor con unos marcos construidos al efecto $^{26} \mathrm{y}$ aseguradas con gran cantidad de clavos, tanto en los márgenes como en el interior del lienzo. Este cortejo celeste acompaña la escena de la calle central del retablo, donde se representa el Calvario, en íntima relación con él (FIGURAS 6 y 7).

Los dos ángeles del lado del Evangelio, de aspecto varonil, portan los elementos más contundentes, una cruz y una columna baja, mientras que los del lado de la epístola, de rostros más finos, sostienen delicadamente una corona de espinas y el paño de la Verónica. Estos ángeles visten túnicas sueltas que dejan al descubierto parte de los brazos y de las piernas. Las extremidades inferiores le sirven al artista para dar sensación de profundidad mediante unos complicados escorzos que resuelve no sin alguna dificultad. La torsión del cuerpo, así como el movimiento de los paños y de las alas, son otras de las soluciones que permiten acrecentar la sensación de dinamismo que pretende el artista. Los rostros, sin embargo, son calmados; los dos

25. Archivo Municipal de Lazkao. Juzgado de paz. Expedientes judiciales. 1533-11, (1718-1719). Autos de la demanda de Juan Echeverría, maestro cantero, contra Miguel Insausti, vecino de Olaberria y administrador de los bienes de Miguel Iztueta, fiscal del Real Protomedicato de Castilla y síndico general de las Descalzas de Madrid por impedirle realizar las obras en los chapiteles de la casa principal de Iztueta conforme a lo convenido.

26. Marcos realizados con unos maderos comprados a Ignacio Beitia. DEAH, Lazkao, San Miguel Arcángel, Libro de fábrica, 1650-1726, s/f. 1710 . 


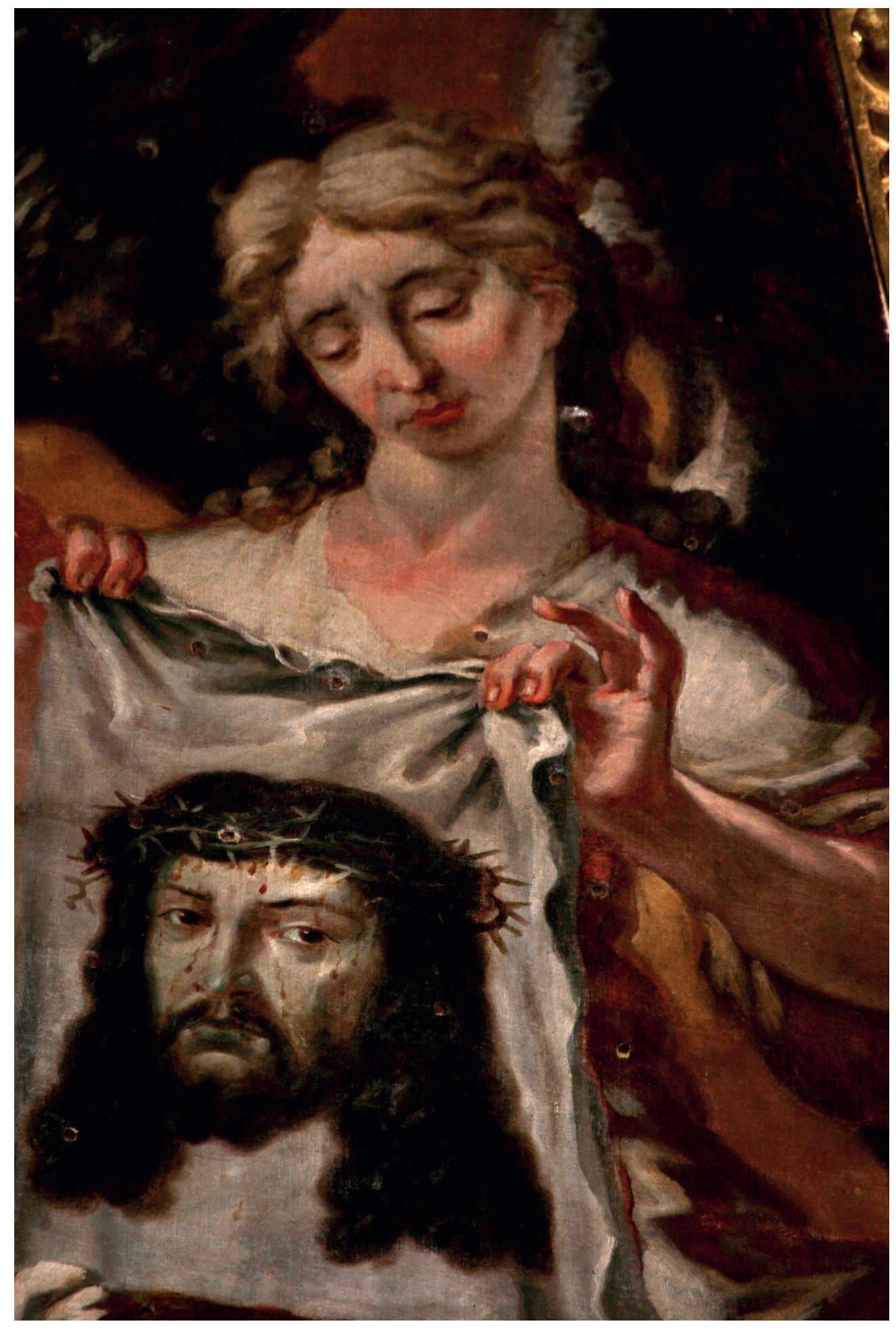

FIGURA 7. DETALLE DE UN ÁNGEL DEL CASCARÓN

Retablo mayor de la iglesia de San Miguel, Lazkao (Gipuzkoa). 
de la derecha poseen unos rasgos dulces, de rostro alargado y aniñado y una frondosa cabellera ondulada dividida en dos con raya en medio y recogida tras la nuca. Los ángeles del lado contrario presentan unas características faciales más duras, con mandíbulas cuadradas y narices anchas. Los cuatro se acomodan en un trono núbeo y despliegan sus alas de forma similar, adoptando una posición efectista.

No hay duda de que el autor de estas pinturas conocía los secretos de la pintura mural decorativa, heredera de las formas giordanescas, donde predominan los escorzos y las perspectivas di sotto in $\mathrm{su}$, como las que podemos advertir en estos ángeles. La técnica empleada es vivaz, deshecha y en ocasiones vibrante, con un colorido de tonos claros y apastelados con fuertes toques de luz. Las composiciones son rotundas y unitarias; los ángeles se adaptan al espacio alargado y curvado de los paños del cascarón, colocando las alas en una difícil posición.

Estas cuatro pinturas, de un barroquismo más avanzado que las anteriormente estudiadas, muestran similitudes formales con algunas figuras de la cúpula de la capilla de las Santas Formas de la iglesia del Colegio Máximo de la Compañía de Jesús de Alcalá de Henares, pintadas por Juan Vicente de Ribera, deudor de los modelos de Antonio Palomino ${ }^{27}$. Esta relación se puede advertir en el tratamiento de los rostros y de los paños volados, algo temblorosos, con mangas amplias recogidas a la altura de los codos. Sin embargo los ángeles de Lazkao poseen un tratamiento más nervioso en los plegados y una paleta menos viva. Nuestras pinturas también pueden relacionarse con otros artistas de escuela madrileña de comienzos del xvılı, por lo que es complicada la atribución, teniendo en cuenta la cantidad de pintores que trabajaron en torno a Felipe $\mathrm{v}^{28}$. Resulta sugerente el hecho de que Juan Bautista, hermano de Miguel de Iztueta, quien donó a la parroquia de Lazkao estas pinturas, fuera guardián de las reales caballerizas de la reina, puesto en el que tuvo un contacto directo con artistas como Juan García de Miranda o Benito Maroto, quienes trabajaron para las caballerizas del Palacio Real de Madrid ${ }^{29}$.

Unos años más tarde, en I768, se decidió sustituir la imagen original del titular del retablo por otro San Miguel Arcángel venciendo al demonio más acorde con los tiempos. Fue tallado por Manuel Martín de Ontañón y su precio incluía el estofado, dorado y conducción desde Pamplona, donde el escultor residía ${ }^{30}$. Es reseñable la gran devoción a San Miguel existente desde el siglo xvı en Gipuzkoa, como se

27. Agradecemos al profesor Ismael Gutiérrez Pastor sus orientaciones sobre estos pintores madrileños. GUTIÉRREZ PASTOR, Ismael: «Juan Vicente de Ribera, pintor (Madrid c. 1668-1736): Aproximación a su vida y obra», Anuario del Departamento de Historia y Teoría del Arte, 6 (1994), pp. 213-238. GALINDO SAN Miguel, Natividad: «El pintor madrileño Juan Vicente de Ribera (h. 1668-1736)», Boletín del Museo del Prado, vol. 15, 33 (1994), pp. 29-52.

28. Pérez SÁNCHeZ, Alfonso Emilio: «Algunos pintores rezagados en el Madrid de Felipe $\vee$ », Archivo español de arte, tomo 58, 231 (1985), pp. 209-229.

29. Jiménez Priego, M. ${ }^{a}$ Teresa: «Artistas de las reales caballerizas del Palacio Real de Madrid», Anales del Instituto de Estudios Madrileños, 19 (1982), pp. 125-150.

30. DEAH, San Miguel Arcángel, Libro de fábrica, 1726-1789, ff. 257, 258v. Sobre el escultor, consultar: GARCíA Gainza, M. ${ }^{a}$ Concepción (dir.): Catálogo Monumental de Navarra. III. Merindad de Olite. Comunidad Foral de Navarra, Institución Príncipe de Viana, 1985, p, 524. Id., Catálogo Monumental de Navarra. $V^{*} *$, Merindad de Pamplona, Imoz-Zugarramurdi. Gobierno de Navarra, Institución Príncipe de Viana, 1996, p. 584. Id., Catálogo Monumental de Navarra. $V^{* * * * *}$, Merindad de Pamplona, Pamplona, índices generales. Gobierno de Navarra, Institución Príncipe de Viana, 1997, pp. 124, 126. 


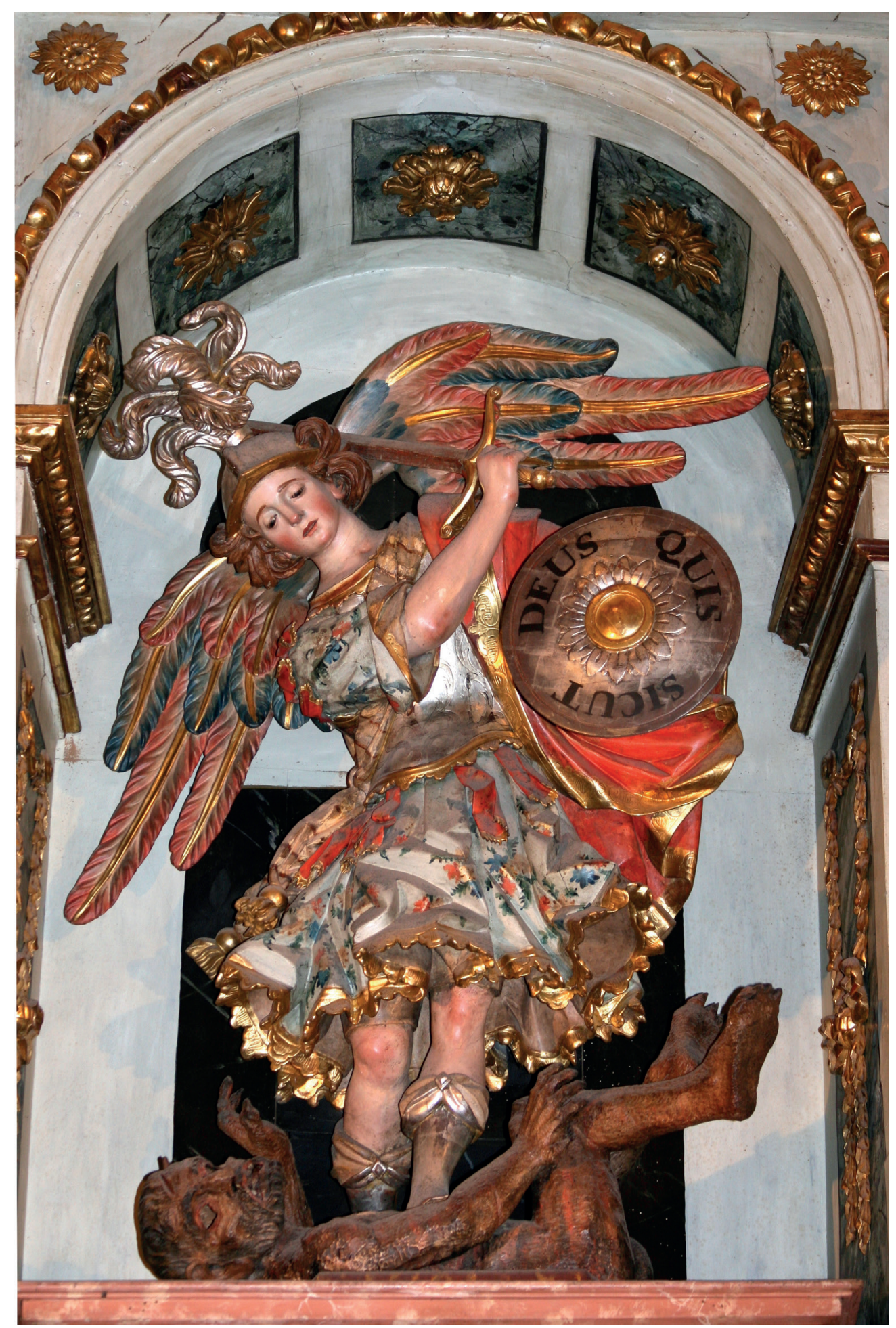

FIGURA 8. SAN MIGUEL ARCÁNGEL

Retablo mayor de la iglesia de San Miguel, Lazkao (Gipuzkoa). 
demuestra en las cerca de cuarenta iglesias y ermitas dedicadas a él ${ }^{\mathrm{I}}$. El arcángel viste a modo de jefe de las milicias celestiales, con coraza plateada, capa roja, faldellín de plegados aristados, grebas y un casco rematado en penacho de plumas sobre su cabeza. En su mano derecha porta una espada y un escudo circular en la izquierda en el que se puede leer «QUiS SICUT DEUS» (quién como Dios). La inestabilidad de su postura y las alas desplegadas ejercen un efecto de gran dinamismo sobre la talla. La policromía responde a las características del rococó, con el uso de motivos florales y labores de medio relieve en las cenefas. En la coraza, el escudo y las grebas emplea plateados bien barnizados para evitar su ennegrecimiento, que buscan imitar el efecto metálico de estos elementos. Unos años más tarde, en I773, la obra fue recompuesta por Miguel Antonio de Jáuregui, escultor de Zegama, y en I774 el pintor tolosarra José de Quintana retocaba algunas partes de su policromía y decoraba también el camarín ${ }^{32}$ (FIGURA 8).

El siguiente cambio llevado a cabo en este retablo fue efectuado en I747, año en el que se concedió licencia para rebajar las gradas del presbiterio y enlosarlo. Esta obra de arquitectura fue diseñada por Ignacio de Ibero y realizada por Juan Bautista de Jáuregui. Para eliminar la diferencia de altura entre el retablo mayor y el nivel de la mesa de altar, dispuso una gradería con molduras, con piedra traída de Ataun $^{33}$. En I77I se solicitó licencia para hacer un pedestal de piedra, ya que «el zócalo del retablo principal de dicha iglesia parece ser de madera y obra mui antigua se halla desmoronado y muy indezente». La traza fue diseñada por Francisco de Ibero y ejecutada en jaspe bruñido y mármol negro por José Joaquín de Arrieta en Azpeitia, en virtud del contrato firmado el I8 de febrero de I772 ${ }^{34}$. Al mismo tiempo se realizó una nueva puerta panelada de acceso a la sacristía, inserta en el propio pedestal, que fue dorada por José de Quintana.

En la última década del siglo xviıl, con la llegada del estilo neoclásico, se produjeron importantes transformaciones en este retablo, que es despojado de toda su talla y policromado en base a los nuevos fundamentos estéticos. Fue Diego Díaz del Valle quien redactó las condiciones para la obra de actualización del retablo de Lazkao, el I4 de septiembre de I790, un año antes de la firma del contrato35. El I4 de octubre de ese mismo año, el arquitecto de la Real Academia de San Fernando

31. Garro Muxika, José Ángel: Dispersión hagiotoponímica hispano-mozárabe en la Diócesis de San Sebastián. http://mendezmende.org/documentos/divulgacion_trabajos/Hagiotoponimia_nueva.pdf. Consultado el 23/03/2013.

32. DEAH, Lazkao, San Miguel Arcángel, Libro de fábrica, 1726-1789, f. 291: 264 reales de vellón a Miguel Antonio de Jáuregui, escultor de Zegama, por cinco días que tardó en poner ojos de cristal a la Virgen de la Esperanza, el Niño, el Niño del Rosario y por la composición del bulto de San Miguel. f. 295V.: A José de Quintana 180 reales de vellón por dar color a la gradería del monumento, 45 por retocar la imagen de la Concepción, 45 por la silla del preste y 30 por encarnar y dar color al bulto de San Miguel en 1774. f. 308: Por la ventana y camarín de San Miguel. f. 314: 1777. 200 reales de vellón a José de Quintana, dorador de Tolosa, por pintura que hizo en el nicho de San Miguel del altar mayor. f. 363: Además de estos trabajos, José de Quintana también se ocupó de la pintura de la mesa de altar de la capilla de la Esperanza, ejecutada «a la romana».

33. Astiazarain, M. ${ }^{a}$ Isabel: Arquitectos guipuzcoanos del siglo xvill. Ignacio de Ibero, Francisco de Ibero. San Sebastián, Diputación Foral de Gipuzkoa, 1990, pp. 10, 161, 163. La gradería tenía que estar acabada para junio de 1748. DEAH, Ibid., f. 127V. A Juan Bautista de Jáuregui, por manufactura de la gradería nueva y algún pequeño reparo en el sagrario. 91.

34. Archivo General de Gipuzkoa (AGG-GAO), PT1933, f. 275; PT3019, ff. 81-83. DEAH, ibid., ff. 280v-281, 285-286v,

35. DEAH, Lazkao, San Miguel Arcángel, Escritura del convenio para el dorado del altar mayor, 1791. 
Alejo de Miranda es llamado por el vicario para revisar las condiciones dadas por el pintor, con el objetivo de mejorar el proyecto. Poco después se introdujeron unas modificaciones, que consistían en incluir un guardavoz para el púlpito, seis jarrones para el remate del retablo y un ostensorio para exponer unas reliquias. Además de todo esto, se añadió un nuevo sagrario, se eliminaron los dos colaterales y se hicieron otras obras para embellecer la iglesia. Todas estas decisiones se habían tomado sin la requerida licencia, por lo que hubo que esperar hasta I79I para que se concediera dicho permiso y finalmente se firmó el contrato el 27 de agosto de I79I con el pintor Diego Díaz del Valle ${ }^{36}$, quien contó con la colaboración de su hermano Gregorio Díaz del Valle, oficial de primera, vecino de Cascante y Tudela, y un oficial de segunda llamado Clemente ${ }^{37}$.

Siguiendo la costumbre arraigada en esta época de adaptar los retablos a las nuevas necesidades estéticas, se tomó la decisión de despojar a este altar de todo aquello que en este momento se consideraba superfluo. El objetivo era actualizar este mueble litúrgico «conforme a la buena idea y gusto de ahora», cumpliendo con las normas establecidas para la policromía y retablística de la época. Estas profundas remodelaciones suponían un lavado de cara del retablo, que afectaban tanto a la arquitectura como al aparato polícromo. En este caso se debía desmontar toda la talla que decoraba la mazonería, dejando tan solo la arquitectura y las columnas corintias originales. Por el contrario, se respetaban las cuatro pinturas del cuerpo central, los ángeles con los atributos de la Pasión del cascarón y la talla titular. Siguiendo este deseo de equilibrar y armonizar al máximo el presbiterio, se decidió eliminar los retablos laterales «por no hacer concordación» y añadir dos mesas de altar «a la romana».

También se sustituía el sagrario antiguo por uno nuevo, a modo de tabernáculo, de planta circular con cuatro columnas, y un ostensorio para presentar la custodia con la forma sagrada los días señalados para ello. Debía colocarse junto al pedestal, a la altura adecuada para poder utilizarlo sin dificultad, dando libertad al maestro para que decorara el tabernáculo con «cristales azogados», es decir, con espejos. Durante el Neoclasicismo, la policromía de los sagrarios fue un tema controvertido entre los maestros con mayor formación intelectual. Para algunos, este edificio

36. Diego Díaz del Valle (Cascante, Navarra, h. 1740 - Viana, Navarra, 1817). La producción de este pintor y arquitecto se concentra entre 1780 y 1817 en diversas localidades de la diócesis de Pamplona, en las que intervino como pintor en policromías de retablos, pintura de caballete y pintura mural. También trabajó como arquitecto y se encargó de dibujar varias trazas. Trabajó en Cáseda, Falces, Viana, Sesma, Tudela, Sangüesa, Uztarroz, Cintruénigo, Corella, Torralba del Río, Liédena, Olite, Pamplona, Cascante o Monteagudo. García Gainza, M. ${ }^{a}$ Concepción (dir.): Catálogo Monumental de Navarra. I, Merindad de Tudela. Gobierno de Navarra, Institución Príncipe de Viana, 2003, pp. 53, 54, 81, 93, 120, 221, 270-271, 325. Id., I1***, Merindad de Estella, Genevilla-Zúñiga. Gobierno de Navarra, Institución Príncipe de Viana, 2005, pp. 486, 530, 565, 571, Id., III. Merindad de Olite. Comunidad Foral de Navarra, Institución Príncipe de Viana, 1985. pp. 84, 290, 293, 294, 298. Id., IV*, Merindad de Sangüesa, Abaurrea Alta-Izalzu. Gobierno de Navarra, Institución Príncipe de Viana, 1989, p. 178. Id., IV**, Merindad de Sangüesa, Jaurrieta-Yesa. Gobierno de Navarra, Institución Príncipe de Viana, 1992, pp. 52, 389, 390, 600. Id., V****, Merindad de Pamplona, Pamplona, índices generales. Gobierno de Navarra, Institución Príncipe de Viana, 1997, pp. 189, 587. Fernández GraCIA, Ricardo: El retablo barroco en Navarra. Pamplona, Gobierno de Navarra, 2004, pp. 116 y 124-125.

37. DEAH, Lazkao, San Miguel, Libro de fábrica, 1788-1856, f. 19. Junto a ellos trabajaron los siguientes maestros: Francisco de Torres, escultor y tallista, vecino de Villafranca de Navarra, quien hizo los adornos de la mesa de altar, aguilones del presbiterio, canapé, sacras de los altares y naveta del púlpito; y Juan Bautista de Iztueta, Juan Pérez de Camino y Gaspar de Sarasola, que participaron en las obras de ensamblaje del retablo mayor. Ibid., ff., 15r, 18v, 19r, 21r. 
sagrado debía formar parte del jaspeado global del retablo, mientras que para otros peritos era más adecuado dorarlo por completo, con lo que se ganaba en hermosu$r a^{38}$. En esta ocasión se optó por la segunda opción, dorando el sagrario completamente y sin intervención de color. Tanto este como el expositor se han eliminado en la actualidad, trasladando el sagrario al retablo colateral del lado de la epístola y situando en su lugar una magnífica pieza en marfil de Cristo crucificado.

Toda la mazonería y los campos del retablo debían imitar el color de la porcelana, salvo el fondo del friso del entablamento, para el que se eligió un jaspe verde de Granada. Para las columnas se reservó un jaspe de piedra de Tortosa, similar al de la Virgen del Pilar de Zaragoza. Todas estas imitaciones pétreas se protegieron con un barniz fuerte para potenciar el color empleado y evitar su degradación. De esta manera, el acabado del altar quedaba en consonancia con el material empleado años atrás para el zócalo, que también se realizó en jaspe.

El aparato decorativo quedaba reducido al máximo. En el remate se colocó el triángulo del tetragrámaton rodeado de nubes y circundado de ráfagas doradas (FIGURA 9) y, en los vaciados, varios motivos de «medio relieve» con formas de inspiración arrocallada, decoraciones en realce que son reminiscencias de la policromía rococó o chinesca. Se trata de trabajos cincelados o grabados sobre los yesos, que crean relieves y se rematan con un dorado de distintas tonalidades. En este caso no acusan un resalte muy pronunciado y se asemejan a palmas y ramas entrecruzadas. Esta misma labor de medio relieve la encontramos en los dos pilastrones del cuerpo central, en los que se reproduce un encadenado de círculos dorados de gusto neoclásico. Otra técnica heredada de época rococó, pero con gran aceptación durante el Neoclasicismo, es la combinación del dorado bruñido y bronceado «para mejor brillantez y hermosura». En este caso se demanda esta técnica para la tarjeta de la calle central del entablamento, sobre la imagen de San Miguel, y es probable que se utilice en todo el aparato decorativo dorado.

En la ejecución de la policromía de este retablo, el pintor Diego Díaz del Valle tuvo en cuenta las anotaciones que el arquitecto Alejo de Miranda le había indicado en I790. Según este arquitecto, las condiciones de Diego Díaz del Valle se habían planteado «con mucha propiedad y buen estilo, arreglado a los bellos preceptos de la arquitectura», pero «con mucha prontitud y deprisa» por las muchas ocupaciones del pintor, lo que hizo que en la obra se detectaran pequeños defectos que enumera el profesor Alejo de Miranda ${ }^{39}$. Entre las recomendaciones de este arquitecto se establece la conveniencia de pintar otro Cristo, añadir en el banco, bajo las columnas, unas cartelas y realizar pequeñas modificaciones en el zócalo. También consideró adecuado mantener los seis jarrones sobre el entablamento y solicitó la supresión de dos mesas de altar pegadas al retablo ${ }^{40}$.

38. Bartolomé García, Fernando R.: «Las claves de la policromía neoclásica», Akobe, 7 (2006), p. 15. BARTOLOMÉ GARCíA, Fernando R.: «Implantación de la policromía neoclásica a través de los modelos cortesanos», en Tabar Anitua, Fernando: Escultura académica en Álava. La escuela de Madrid del siglo xvIII, (Catálogo de exposición). Vitoria, 2007, pp. 196-225.

39. DEAH, Lazkao, San Miguel Arcángel, Escritura del convenio para el dorado del altar mayor, 1791, s/f.

40. No fue la única transformación que realizó Diego Díaz del Valle. Un ejemplo similar encontramos en el retablo mayor de la antigua colegiata de Borja (Aragón). BoLOQUI LARRAYA, Belén: «Construcción y reforma del 


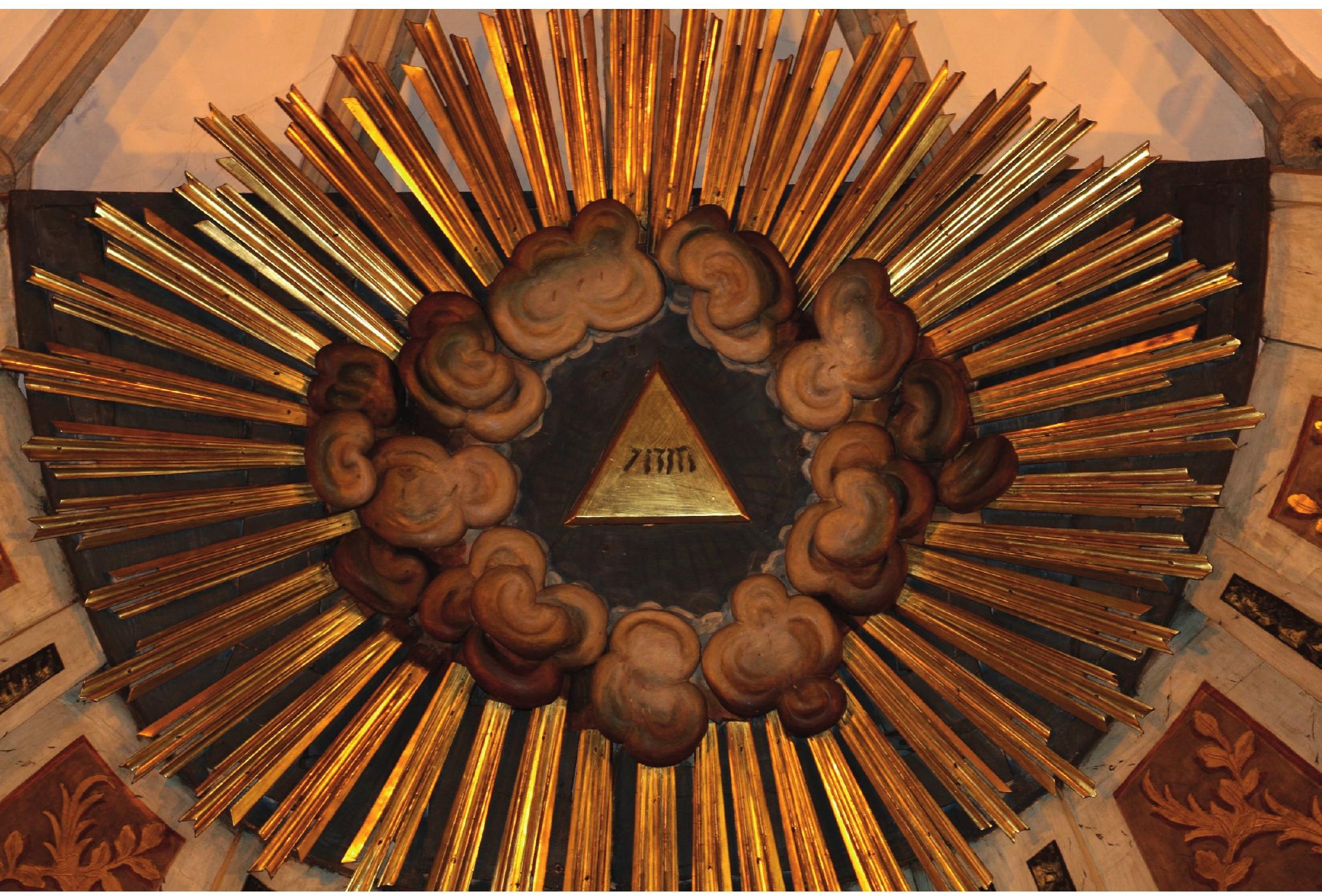

FIGURA 9. TETRAGRÁMATON DEL CASCARÓN

Retablo mayor de la iglesia de San Miguel, Lazkao (Gipuzkoa).

Para el banco se realizaron cuatro pinturas sobre tabla de formato apaisado y de la misma anchura que los lienzos del cuerpo principal. En ellas se representa a las nuevas devociones: San Ignacio de Loyola, fundador de la orden de los jesuitas; San Martín de Loinaz, mártir de gran devoción en la comarca; un santo obispo y

retablo mayor de la Asunción de la Ex-Colegiata de Santa María de Borja. Gregorio y Antonio de Mesa (1683-1704) y Santiago Marsili y Diego Díaz del Valle (1782-1783)», Seminario de Arte Aragonés, 31 (1980), pp. 105-135. También presenta informes para otras reformas neoclásicas en las iglesias de Villafranca (Navarra) y en la capilla de San Fermín de la iglesia de San Lorenzo de Pamplona. LACARRA YANGuAS, M. ${ }^{a}$ Jesús: «Puntualizaciones históricas sobre las Iglesias de Villafranca», Actas del I Congreso General e Historia de Navarra, Príncipe de Viana, anejo 11 (1988), p. 304. MoLINS Mugueta, José Luis: Capilla de San Fermín en la Iglesia de San Lorenzo de Pamplona. Pamplona, Diputación Foral de Navarra, Ayuntamiento de Pamplona, 1974. 
San Francisco Javier, otro santo jesuita cuyo culto admitió un gran auge durante el Barroco y el Neoclasicimo.

Según las condiciones que estableció Diego Díaz del Valle, la obra tendría un coste de I6ooo reales, que se debían pagar en tres plazos ${ }^{41}$. Alejo de Miranda consideró esta cantidad muy baja para todo el trabajo que se debía realizar y por ello se sumaron 6044 reales más que, unidos a los I600o, hacían un montante de 22044 reales. Finalmente la obra quedaba finiquitada el día I3 de agosto de I793. Para efectuar este pago la iglesia tuvo que recurrir a la petición de varios censos, lo que motivó que, aún en I8I9, se siguieran liquidando cuentas del retablo ${ }^{42}$.

La última de las modificaciones que ha sufrido este retablo tiene que ver una vez más con su policromía. En documentos fotográficos del siglo xx consultados en el Servicio de Restauraciones de la Diputación de Gipuzkoa ${ }^{43}$ podemos observar que posteriormente a I79I las partes que imitaban mármol blanco fueron cubiertas por una repolicromía jaspeada que se conservó hasta I992, cuando fue eliminada en la restauración que en ese año realizó la empresa Andra Mari.

En conclusión, en este estudio ponemos en valor el retablo mayor de Lazkao, fechado en I683, que hasta ahora se creía desaparecido. Hemos podido documentar los cambios que durante más de un siglo se fueron realizando y que modificaron su aspecto hasta hacerlo casi irreconocible. No obstante, la estructura del retablo sigue evidenciando sus raíces barrocas en la disposición de cascarón, en su dinámico entablamento y en los grandes lienzos del cuerpo principal. Entre los cambios efectuados para dotarlo de mayor suntuosidad resaltamos las pinturas de escuela madrileña que decoran el cascarón y que fueron introducidas a comienzos del xvill y la adecuación neoclásica que se realizó en I79I de manos del pintor navarro Diego Díaz del Valle, quien mediante la eliminación de la decoración y la aplicación de una policromía de imitaciones pétreas supo actualizar este altar a las nuevas corrientes neoclásicas del momento.

41. DEAH, Ibid, s/f. Se manda que se paguen «6000 reales ahora de contado, 5000 a la mitad y 5000 al fin». Los andamios corrían a cargo de la iglesia.

42. DEAH, Lazkao, San Miguel Arcángel, Libro de fábrica, 1788-1856, ff. 18, 90-93V.

43. Agradecemos a Xabier Martiarena Lasa, restaurador de la Diputación Foral de Gipuzkoa, las imágenes del retablo de Lazkao anteriores a su restauración de 1992. 


\section{Dossier Cómplices Necesarios por Carlos Reyero Hermosilla - Dossier Necessary Accomplices by Carlos Reyero}

2) CARLOS REYERO

Introduction: Necessary Accomplices / Presentación: Cómplices necesarios

25 Encarna Montero Tortajada

The Oligarch and the Brushes: a Biographical Sketch of Andreu Garcia, priest / El oligarca y los pinceles: breve semblanza del presbítero Andreu Garcia

María Alegra García García

Some aspects about archbishop of Toledo don Juan Martínez Silíceo's iconography (c.1477-1557) / Algunos aspectos en torno a la iconografía del arzobispo de Toledo don Juan Martínez Silíceo (c.1477-1557)

\section{FELIPE PEREDA}

Performing Doubt: the Art of Believing in Early Modern Spain / El ejercicio de la duda: el arte de creer en la España alto Moderna

\section{Jesús-PEdRo LoREnTE LORENTE}

The mouseion ideal reinterpreted as art colony on the outskirts of Darmstadt and Hagen / El ideal del mouseion reinterpretado como colonia artística en las afueras de Darmstadt y Hagen

\section{9}

NÚRIA FERNÁNDEZ RIUS \& NURIA PEIST

The photographic and the mediation system. Artistic, technical and commercial values in the beginning of photography / Lo fotográfico y el sistema mediador. Valores artísticos, técnicos y comerciales en los inicios de la fotografía

\section{Elena Marcén Guillén}

Real museum, imaginary museum. Considerations around the concept of museum as metamorphosis scenery / Museo real, museo imaginario. Reflexiones en torno al concepto de museo como escenario de metamorfosis

147 VICENÇ FURIÓ

Fame and prestige: necessary and decisive accomplices in the case of Hilma af Klint / Fama y prestigio: cómplices necesarios y decisivos en el caso de Hilma af Klint

\section{Miscelánea $\cdot$ Miscellany}

De la aljama a la primitiva construcción gótica. Reflexiones a propósito de la Catedral de Jaén en época bajomedieval / From the Great Mosque to the former Gothic construction. Some observations on Jaén's Cathedral during the late middle ages
199

TERESA IZQUIERDO ARANDA

Carpintero y maestro constructor en la arquitectura gótica valenciana / Carpenters and building mason in the Gothic architecture in Valencia $\left(14^{\text {th }}-15^{\text {th }}\right.$ centuries)

223

ANTONIO JosÉ DíAZ FERNÁNDEZ

El arquitecto madrileño Pedro de la Torre en Toledo y un retablo inédito localizado / The Architect of Madrid Pedro de la Torre in Toledo and a located unpublished altarpiece

24.7 Fernando R. Bartolomé García \& Laura Calvo García

Transformaciones en el retablo mayor de San Miguel Arcángel de Lazkao (Gipuzkoa). Del Barroco al Neoclasicismo / Changes in the main altarpiece of Saint Michael the Archangel in Lazkao (Gipuzkoa). From Baroque to Neoclassicism

\section{Francisco JaVIER LÁZARO SEBAStiÁN}

La renovación de la fotografía española a partir de la pauta estética del realismo. Un precedente formal y significativo en el reportaje de Eugene Smith sobre Deleitosa (Cáceres) / The renovation of the Spanish photography from the aesthetic guideline of the realism. A formal and significant precedent in Eugene's Smith photographic article on Deleitosa (Cáceres)

277 Javier Cuevas del Barrio

El posicionamiento de Sigmund Freud ante el Surrealismo a través de la correspondencia con André Breton / The position of Sigmund Freud regarding Surrealism through correspondence with André Breton

295 Alicia SÁnCHEZ ORTIZ

El vacío iluminado del negro / The illuminated void of black

317 Óscar MuÑoz Sánchez

Santiago Serrano (1970-1980): Hacia una pintura no aprehensible / Santiago Serrano (1970-1980). Towards a non-apprehensible painting

347 Antonio Jesús Sánchez FERnÁndeZ

Restauración y metamorfosis de los valores del patrimonio cultural / Restoration and Metamorphosis of the Values of Cultural Heritage

\section{Reseñas · Book Review}

375

Aricò, Nicola. Architettura del Tardo Rinascimento in Sicilia. Giovannangelo Montorsoli a Messina (1547-57). Firenze, Leo S. Olschi Editore, 2013. (AlICIA CÁmARA MuÑoz)

Combalía, Victoria. Dora Maar. Barcelona, Circe, 2013. (AMPARO SERRANO DE HARO)

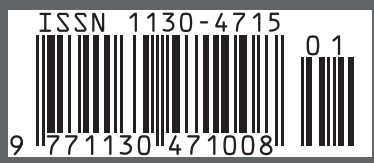

